\title{
NUMERICAL EVALUATION OF THERMO-HYDRAULIC PERFORMANCE INDEX OF A DOUBLE PIPE HEAT EXCHANGER USING DOUBLE SIDED LOUVERED WINGLET TAPE
}

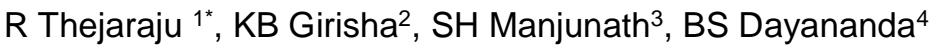

\begin{abstract}
The decade has witnessed great importance of numerical techniques for scientists and researchers in deciding the correctness, stability, and reliability of new designs. In the present study a numerical technique has been implemented to investigate the thermo-hydraulic performance of the Louvered winglet tape inside the tube section of the double pipe heat exchanger. The Louvered winglet tape has been examined with the slope angle of 50, 100, 150 and 210 to study their thermal characteristics. The Reynolds number 4000-30000 was examined on slope angle of 50, 100, 150 and 210 to study their flow characteristics in the turbulent domain. A smooth pipe was examined to evaluate heat transfer characteristics in terms of Nusselt number and friction coefficient over augmented tube with Louvered winglet tape. The results show a satisfactory performance of Louvered winglet tape over the smooth tube with a similar trend of friction factor, Nusselt number, and thermo-hydraulic performance index (THPI). The percentage of increment of the Nusselt number of the results is found to be $237.04 \%, 258.4 \%, 275.11 \%$, and $289.72 \%$ when compared to smooth pipe with respect to slope angle of 50,100, 150 and 210, respectively. The amount of increase in the friction factor in comparison with plain tube is $5.13,6.73,8.33$, and 11.73 times of that of smooth pipe with respect to slope angle of $50,100,150$ and 210, respectively. The Louvered winglet tape with slope angle 150 has shown to be promising with respect to higher THPI when considering with other slope angle of 50, 100, and 210. The maximum THPI of 1.85 was obtained for slope angle 150 at Re 12000. Similarly, the THPI values for other slope angle 50, 100, and 210 are 1.71, 1.78 and 1.69. In addition to better performance the Louvered winglet tape can be easily fabricated and adapted for a wide variety of heat transfer industries.
\end{abstract}

Keywords: Numerical Technique, Louvered Winglet Tape, Thermo-Hydraulic Performance Index, Slope Angle

\section{INTRODUCTION}

From olden days it was always foreseen from the scientists and engineers that the industries get the best heat equipment devices for their heat transfer process. Today industries like petroleum, cement, pharmaceuticals, power, medical devices, cooling solutions, and sustainable energy fields are always looking for optimized heat transfer techniques to overcome them given task in a better way. So double pipe heat exchanger (DPHE) is one of the simplest types of heat exchanger which has its application in diverse fields.

For improvising the efficiency of the heat transfer process in the heat exchangers, enhancement techniques are most welcome in designing the compact heat exchangers, supercritical boilers and chilling plates. Insertion of fins, tapes, strips, coiled wire, swirl generators, vortex generator, and wire mesh are some of the passive types of optimization techniques which are adopted by numerous researchers. The main aim of adopting an optimization technique is to increase the heat transfer (Nusselt number) and decrease the pumping power (friction factor) by creating the disturbance in thermal and velocity boundary layer.

The Delta winglet type (DWT) tape inserts are one of the unique insertion methods which have found its place in various applications. The inserts can be manufactured easily with a more economical way with next to the twisted

This paper was recommended for publication in revised form by Regional Editor Erman Aslan

$I^{*}$ Department of Mechanical Engineering, VTU Belgaum, 590018, India.

2 Department of Mechanical Engineering, BGSIT-Adichunchanagiri University, BG Nagara, 571448, India.

${ }^{3}$ Department of Mechanical Engineering, BGSIT-Adichunchanagiri University, BG Nagara, 571448, India.

${ }^{4}$ Department of Mechanical and Manufacturing Engineering, MS Ramaiah University of Applied Sciences, Bangalore, Karnataka 560054, India.

${ }^{*} E$-mail address: thejaraju.r@gmail.com

Orcid id: 0000-0002-9170-3873, 0000-0002-4893-1627, 0000-0002-5113-4223, 0000-0003-1230-029X

Manuscript Received 06 September 2019, Accepted 08 February 2020 
tape. Some of the recent works on DWT are the study on thermal performance characteristics of Double-sided Deltawing Tape Insert by Smith[1] showed that the heat transfer increase with the increase in wing-width ratio and decrease in the wing-pitch ratio, and achieved a maximum thermal performance factor of 1.29 with a forward wing arrangement. Promvonge [2] $60^{\circ}$ winglet pair insert experimented under airflow conditions from Reynolds number 5300-24000. The variation of enhancement factor was from 1.03-1.31 with respect to different pitch and blockage ratios. The effects of different arrangement of delta winglet vortex generators (DWVG) was investigated by Aliabadi [3] in comparison with a plain tube with water as a testing fluid. The maximum performance enhancement criteria (PEC) of 1.41 were achieved from DWVG class 4 vortex generator. Wavy-ribs vortex generator (VG) by Withada [4] proved to be one of the augmented method in heat exchanging system with a maximum PEC factor of $1.47-1.52$ at Re 3000 for $30^{\circ}$ and $45^{\circ}$ ribs.

A new design of DWT by Skullong [5] on air flow had obtained an overall optimization of 1.48 for an inclination angle of the wing of $30^{\circ}$ and pitch ratio 1. Withada's [6] punched DWVG proved better heat transfer rate for the laminar flow with an optimization factor of 2.8 for Re 2000 and angle of attack $25^{\circ}$. Staggered-winglet by Skullong [7] proved to be one of the augmentation technique which has its maximum enhancement factor of 1.71 at $\operatorname{Re} 4180$, baffle ratio 0.15 and pitch ratio 1 . Skullong perforated-Curved-winglet tape[8] investigation reveals that the maximum PEC is about 1.62 for a baffle ratio of 0.1 and pitch ratio 1. A triple wing VG by Gautam [9] was tested under a circular tube showcasing a maximum improvement of 1.63 in the overall performance.

Some of the other VG designs which influenced the heat transfer rate and flow friction are winglet VG by Islam[10,11], punched DWVG by Lei[12], Wijayanta [13], Skullong [14], double-sided DWT by Wijayanta [15,16] and flow divider type turbulators by Sandeep [17] are some of the recent augmented techniques. A Stepped conical Nozzle turbulators was designed by Orhan [18] saw an overall optimization of $11 \%$ compare to plain tube. Nanofluids are also used in heat exchanger with augmented techniques to hence to overall performance. Recently, Bayareh [19] have shown a significant rise in Nusselt number with corrugated tube and Water-CuO nanofluid. Triangular twisted tape with nanofluids by Pavan Kumar [20] has also that compound method with inserts and nanofluid can result in better optimization.

Based on the past research it shows that heat transfer can be optimized by modifying the geometric of insert, provide better recirculation, resulting in proper mixing and increase in the flow path. The VGs and DWTs are usually used to produce the vortices and recirculation in a longitudinal direction. The main advantage of louvered winglet tape insert (LWT) is that the THPI can be increased from 1.35 to 1.85 times over plain tube. The louvered shape was first investigated as an insert by smith[21] to study DPHE with forward and backward arrangement experimentally, later a numerical study was carried out by Liu[22] to study its parametric effect of slant angle and pitch in a circular tube. Recently a comparison study was carried out between different shapes of inserts over louvered shape insert by Yaningsih[23]. Motivated by the above facts, louvered shape proves to be one of key geometric design to increase the heat transfer rate. So the current study involves the applications of the louvered shape in winglet tape insert for augmenting the DPHE in optimizing the heat transfer with reduced pressure drop. The current study aims to investigate numerically the effect of pressure drop and heat transfer characteristics of the LWT in the DPHE. The study quantifies the effect of different slant angle of double-sided louvered winglet tape on the heat transfer rate from $\operatorname{Re} 6000$ to $\operatorname{Re}$ 30000 .

\section{PHYSICAL MODEL}

The numerical model adopted for cfd analysis is as shown in figure (1). Where the figure 1(a) shows the crosssection view of LWT inside a DPHE from the front view and side view. The DPHE has two major sections in its configuration, namely tube section, and shell section. The working fluid throughout the simulation is air; the hot air passes in the tube section with LWT and cold air passes at the shell. A counter-flow phenomenon is adopted because of its uniform temperature difference over the entire length of the flow path between the fluids. 


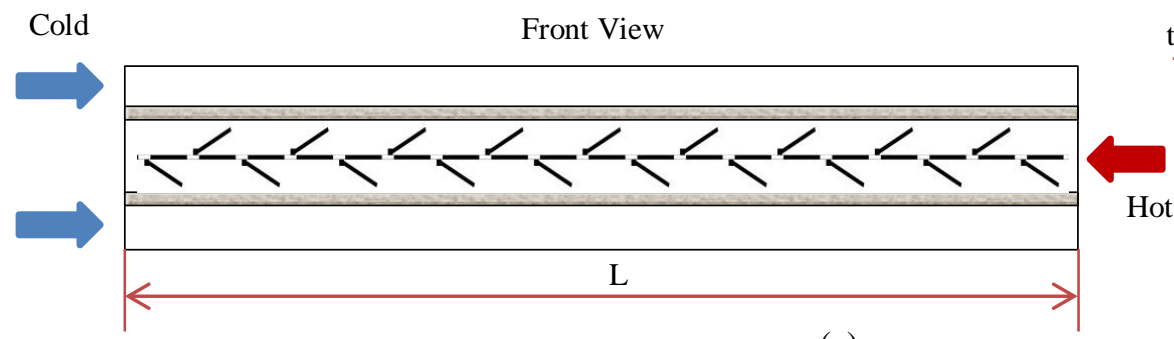

(a)

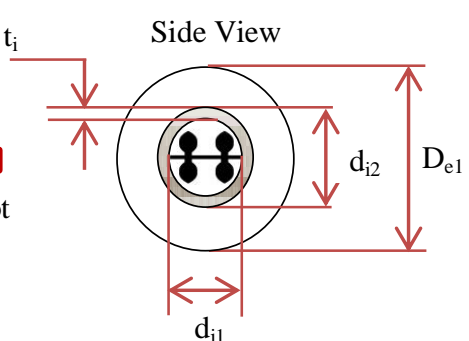

$\mathrm{d}_{\mathrm{i} 1}$
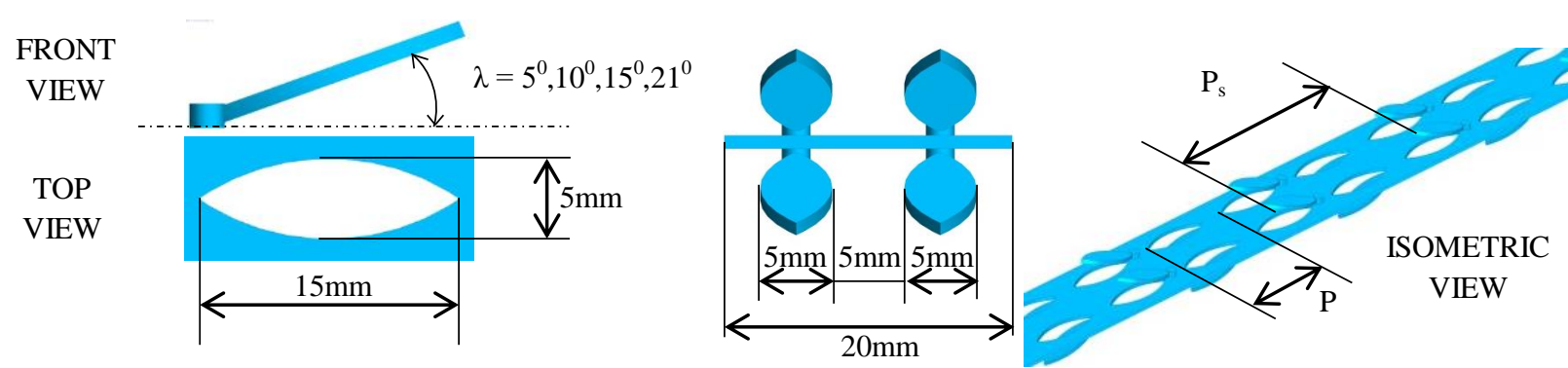

(b)
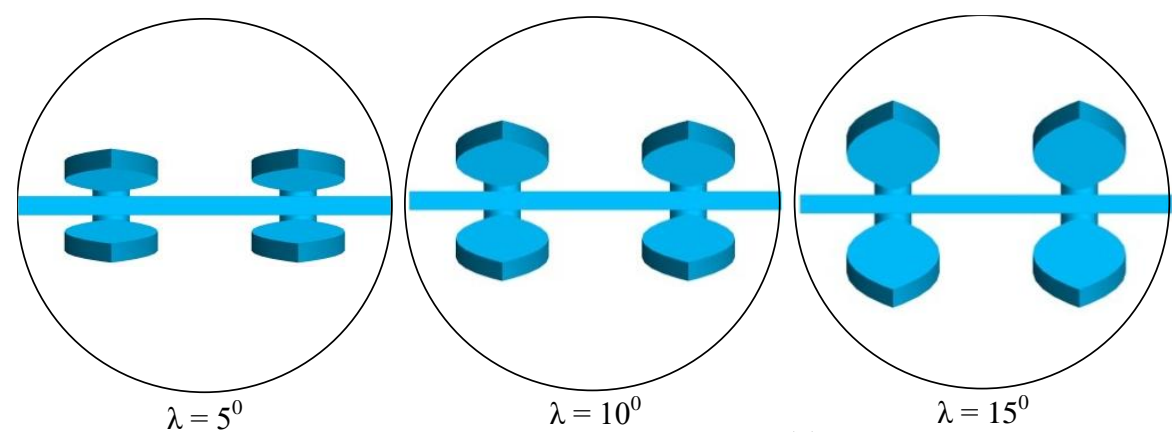

(c)

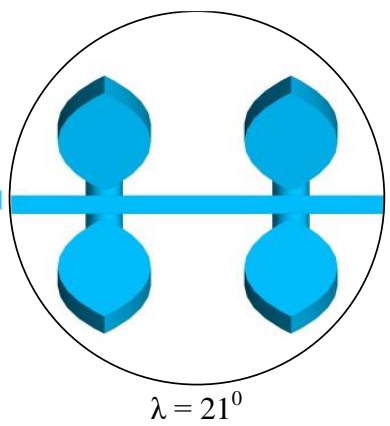

Figure 1. (a) Section view of DPHE with LWT (b) Geometric details of LWT (c) Side view of LWT at different slope angle

Figure 1(b) displays the details and arrangement of the LWT inside the DPHE. The investigation of LWT was carried off with a slope angle of $5^{0}, 10^{\circ}, 15^{\circ}$ and $21^{\circ}$. The isometric view of the winglet tapes shows the pitch length between two consecutive inserts. The side view of LWT at different slope angle inside the tube is showcased in figure 1(c). The geometric details of the numerical model are listed in table 1 .

Table 1. Geometric details of DPHE

\begin{tabular}{|c|c|c|}
\hline Parameter & Value & Dimension \\
\hline \multicolumn{3}{|c|}{ Tube } \\
\hline Outer Diameter & 22 & $\mathrm{~mm}$ \\
\hline Inner Diameter & 20 & $\mathrm{~mm}$ \\
\hline Length & 1200 & $\mathrm{~mm}$ \\
\hline \multicolumn{3}{|c|}{ Shell } \\
\hline Outer Diameter & 42 & $\mathrm{~mm}$ \\
\hline Inner Diameter & 40 & $\mathrm{~mm}$ \\
\hline Length & 1200 & $\mathrm{~mm}$ \\
\hline
\end{tabular}


The thickness of the tube and LWT insert was maintained at $1 \mathrm{~mm}$ throughout. The pitch between two consecutive inserts on the opposite side is $20 \mathrm{~mm}$ and on the same side, it is $40 \mathrm{~mm}$. A constant pitch was maintained throughout the analysis. The material used for the tube in the cfd analysis was aluminum. The detail properties of aluminum and air at different temperature are shown in table 2 and were assumed to be temperature independent.

Table 2. Property details of air and aluminum

\begin{tabular}{|c|c|c|c|c|c|l|l|c|}
\hline & T in K & $\rho$ in $\mathrm{Kg} / \mathrm{m}^{3}$ & $\begin{array}{l}\mathrm{C}_{\mathrm{P}} \text { in J/kg } \\
. \mathrm{K}\end{array}$ & $\begin{array}{l}\Gamma \text { in } \mathrm{W} / \mathrm{m}- \\
\mathrm{K}\end{array}$ & $\alpha$ in $\mathrm{m}^{2} / \mathrm{s}$ & $\begin{array}{l}\mu \text { in } \mathrm{Kg} / \mathrm{m}- \\
\mathrm{s}\end{array}$ & $v \mathrm{in} \mathrm{m}^{2} / \mathrm{s}$ & $\operatorname{Pr}$ \\
\hline Hot Air & 360 & 0.9719 & 1008 & 0.03024 & $3.086 \mathrm{e}-5$ & $2.139 \mathrm{e}-5$ & $2.201 \mathrm{e}-5$ & 0.71 \\
\hline Cold Air & 300 & 1.184 & 1007 & 0.02588 & $2.141 \mathrm{e}-5$ & $1.849 \mathrm{e}-5$ & $1.562 \mathrm{e}-5$ & 0.72 \\
\hline Aluminum & - & 2719 & 871 & 202.4 & - & - & - & - \\
\hline
\end{tabular}

The flow parameters at the inlet of the shell and tube sections are defined by Reynolds number which can be defined as:

$$
R e=\frac{\rho U_{i} d_{i 1}}{\mu_{f}}
$$

Where, $\mu_{f}$ is the dynamic viscosity of the fluid, $d_{i 1}$ is the inner diameter of the tube, $U_{i}$ is the inlet velocity of the tube and $\rho$ is the fluid density. The Reynolds number for tube side has been varied from 4000 to 30000 and at the shell side, it is fixed for 6000 . The heat transfer coefficient is determined by the Nusselt Number which defined as:

$$
N u=\frac{h_{i} d_{i 1}}{\Gamma}
$$

Where, $\Gamma$ is thermal conductivity of the fluid, $d_{i 1}$ is the inner diameter of the tube and $h_{i}$ is the heat transfer coefficient at the tube. The power lost due to the pumping of fluid through the tube can determine by the friction factor, which is defined as:

$$
f=\frac{\Delta \mathrm{P}}{\left(\rho U_{i}^{2} / 2\right)\left(L / d_{i 1}\right)}
$$

The pressure drop is evaluated between the inlet and outlet of the tube, which intern predicts the friction factor.

\section{NUMERICAL METHOD}

Cfd technique was used to model the present fluid domain. The technique incorporates mainly three important governing equations continuity equation, momentum equation, and energy equation. Where the continuity equation describes the conservation mass, momentum equation describes the conservation of forces and energy equation describes the conservation of energy (temperature). The governing equations are as follows:

Continuity Equation:

$$
\frac{\partial}{\partial x_{i}}\left(\rho u_{i}\right)=0
$$

Momentum Equation:

$$
\frac{\partial}{\partial x_{i}}\left(\rho u_{i} u_{k}\right)=\frac{\partial}{\partial x_{i}}\left(\mu_{f} \frac{\partial u_{k}}{\partial x_{i}}\right)-\frac{\partial p}{\partial x_{k}}
$$


Energy Equation:

$$
\frac{\partial}{\partial x_{i}}\left(\rho u_{i} T\right)=\frac{\partial}{\partial x_{i}}\left(\frac{\Gamma}{c_{p}} \frac{\partial T}{\partial x_{i}}\right)
$$

Where, $\rho$ is the density of the fluid, $u$ is the mean component velocity, $p$ is the pressure, $\mu_{\mathrm{f}}$ is the dynamic viscosity of the fluid, $\mathrm{Cp}$ is the specific heat, $\Gamma$ is the thermal conductivity of the fluid, and $\mathrm{T}$ is the temperature. The subscripts $\mathrm{i}$ and $\mathrm{k}$ indicate that the direction is towards $\mathrm{i}$ and $\mathrm{k}$.
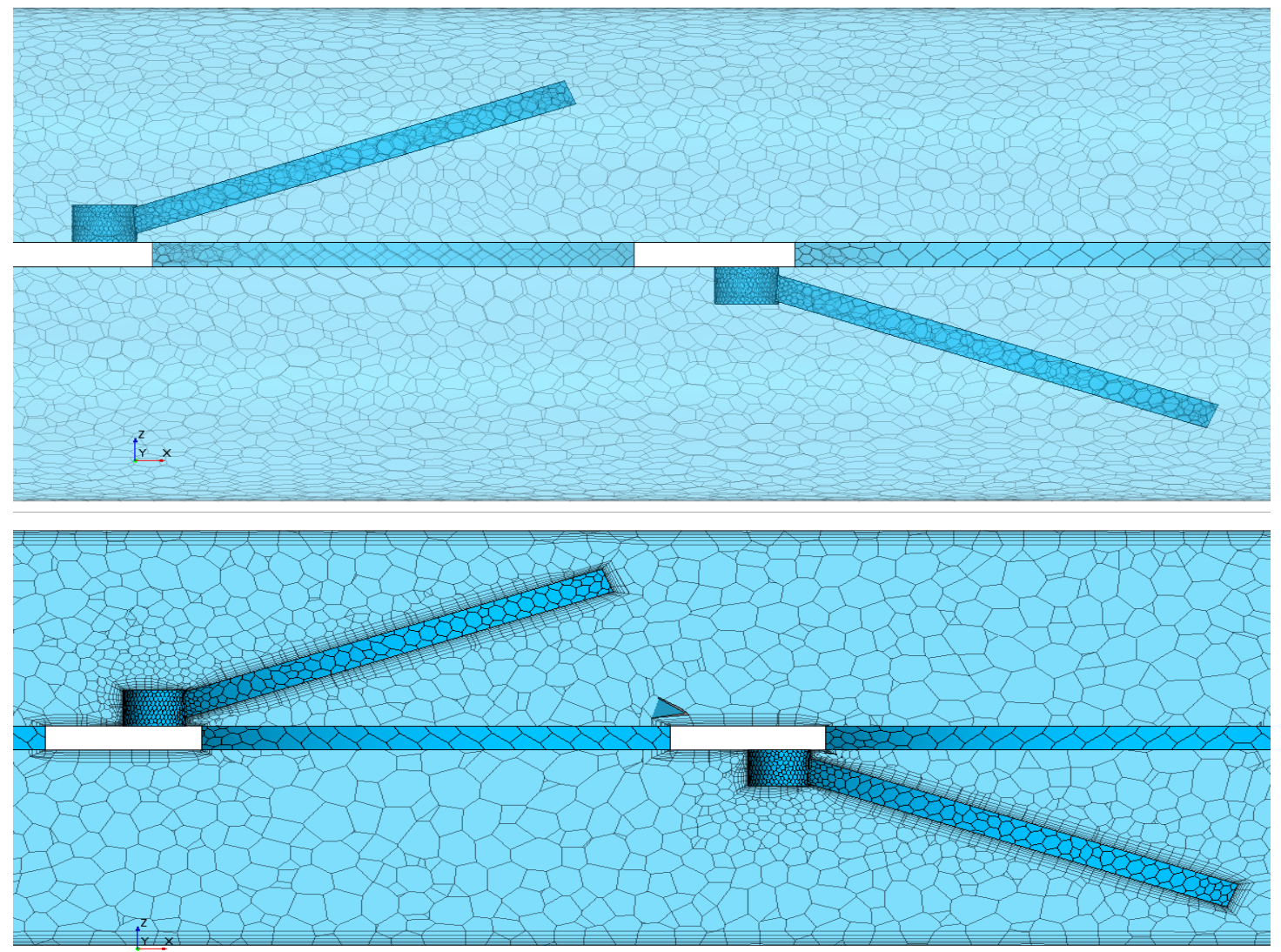

(b)

Figure 2. (a) Surface mesh (b) Boundary layer mesh

The numerical problem was solved as a three dimensional, steady-state, incompressible and turbulent heat transfer flow problem. STAR-CCM+ V13.06 cfd software was used to solve the domain with the above conditions. Figure 2 (a) shows the polyhedral mesh which is generated over the surface and figure 2 (b) shows the boundary layer meshing of the domain near the wall and the inserts. The models applied in STAR-CCM+ to solve the fluid domain are RANS model with realizable k-epsilon two-layer, segregated flow with exact wall distance and segregated fluid temperature on energy. The segregated solid energy model was used to solve the heat transfer calculations with solid.

Velocity inlet boundary conditions were applied for inlet of tube and shell based on the Reynolds number. Coupled boundary condition was assigned for the interface boundaries between solid and fluid domains. Pressure outlet condition was applied for the outlets. Temperature for the hot and cold fluid was assigned as the inlet conditions along with the velocity. The no-slip condition was applied for the walls and adiabatic condition was applied to the walls exposed to the outer atmosphere. Surface custom control technique was adopted in STAR-CCM+ for automated grid generation. 
Journal of Thermal Engineering, Research Article Vol. 6, No. 5, pp. 843-857, October, 2020

\section{RESULTS AND DISCUSSION}

Usually, the augmented heat exchangers performance is measured by their thermal-hydraulic performance index. From past studies, the thermal-hydraulic performance index can also be called as enhancement efficiency, overall thermal enhancement ratio, thermal enhancement factor, thermal performance factor, overall heat transfer enhancement ratio, and performance index. The value of thermal-hydraulic performance index is important for an insert and, which wholly depends on friction factor and Nusselt number. For a good insert, the value of thermalhydraulic performance index should be always greater than unity. In order to obtain higher values of thermal-hydraulic performance index the proposed insert should produce maximum Nusselt number with minimum possible pressure drop (friction factor).

\section{Grid generation and Empirical relations}

Based on past research the slope or slant angles of the inserts are selected with respect to the tube diameter and length of the insert. For the present case, with constant pitch the diameter of tube is $20 \mathrm{~mm}$ and length of the insert is $15 \mathrm{~mm}$. So the maximum possible slope angle for LWT is $21^{\circ}$ beyond which, it was coinciding with the tube surface. The minimum slope angle of $5^{0}$ was selected based on the performance of the heat exchanger as below that there was not much improvement in the thermal-hydraulic performance index. At last the heat exchanger with LWT was investigated for slope angles of $5^{0}, 10^{\circ}, 15^{0}$ and $21^{\circ}$. The maximum slope angle of $21^{0}$ is chosen for the analysis instead of $20^{\circ}$ because the variations in the value of Nusselt number and friction factor were minimal. The intention was to observe the performance of LWT at its maximum possible slope angle for different flow conditions.

The grid was generated for four different sizes to examine the independency test of the mesh. The mesh was generated for slope angle of $5^{0}, 10^{0}, 15^{0}$ and $21^{0}$ at all the Reynolds number varying from 4000 to 30000 . Figure 3 shows a sample case at Reynolds number 12000 with the variation of Nusselt number with respect to different grid size. The grid sizes which were tested were 1e7, 2e7, 4e7 and 8.5e7. The Nusselt number variation between grid size 4e7 and 8.5e7 was found to be less than $1 \%$. So the grid size of $4 \mathrm{e} 7$ was used for further analysis with different flow conditions.

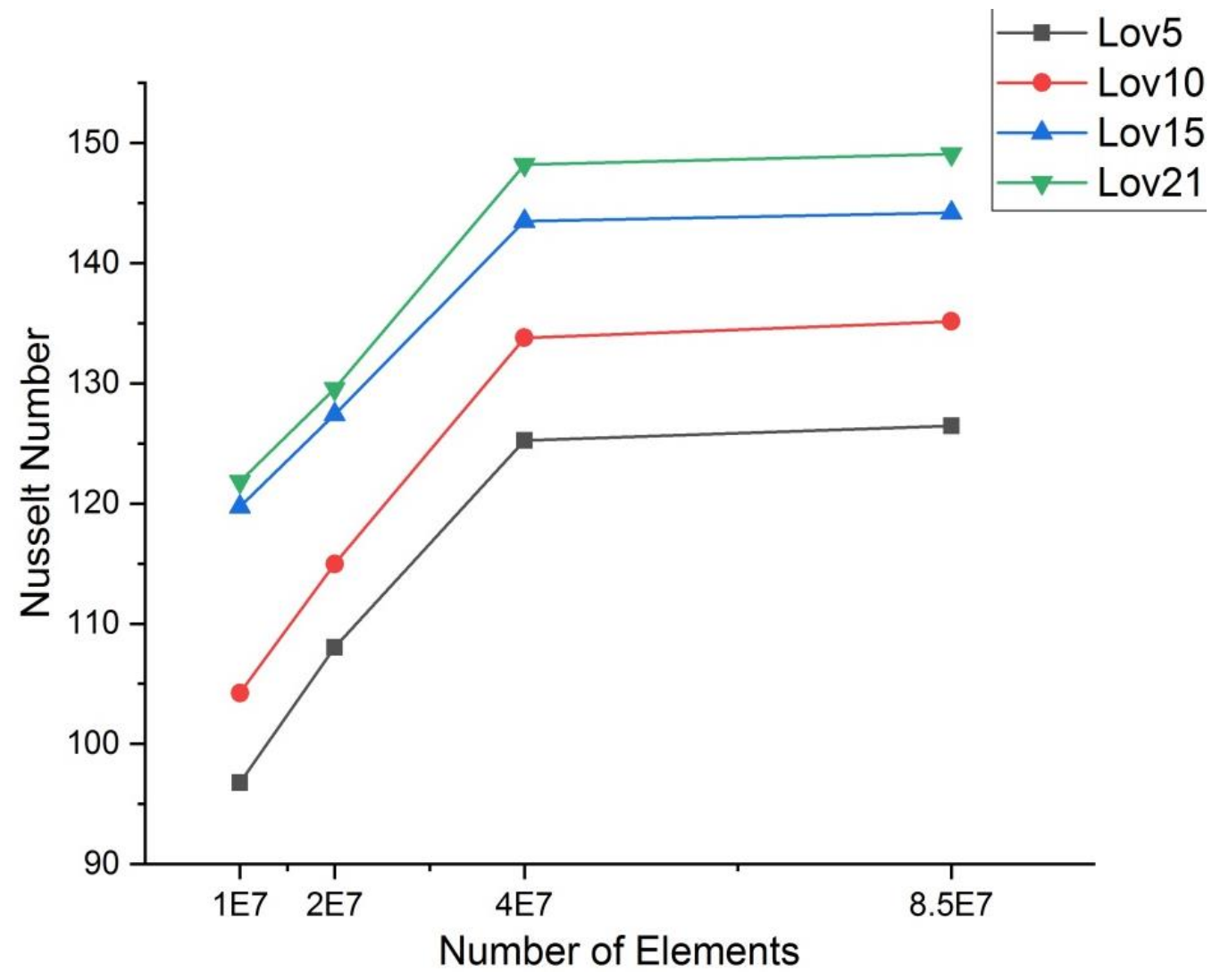

Figure 3. Grid independency test at $\operatorname{Re}=12000$ 
Journal of Thermal Engineering, Research Article Vol. 6, No. 5, pp. 843-857, October, 2020

Nusselt number is one of the dimensionless parameters which is used for measurement of heat transfer coefficient in heat transferring devices. The Dittus-Boelter and Gnielinski equations are extensively used for determining the Nusselt number in a smooth tube.

The Dittus-Boelter equation for $10^{4}<\operatorname{Re}<5 \times 10^{6}$ :

$$
N u=0.023(R e)^{4 / 5}(P r)^{1 / 3}
$$

Gnielinski equation for $1 \times 10^{3}<\operatorname{Re}<5 \times 10^{6}$ :

$$
N u=\frac{(f / 8)(R e-1000) P r}{1+12.7(f / 8)^{1 / 8}\left(\operatorname{Pr}^{2 / 3}-1\right)}
$$

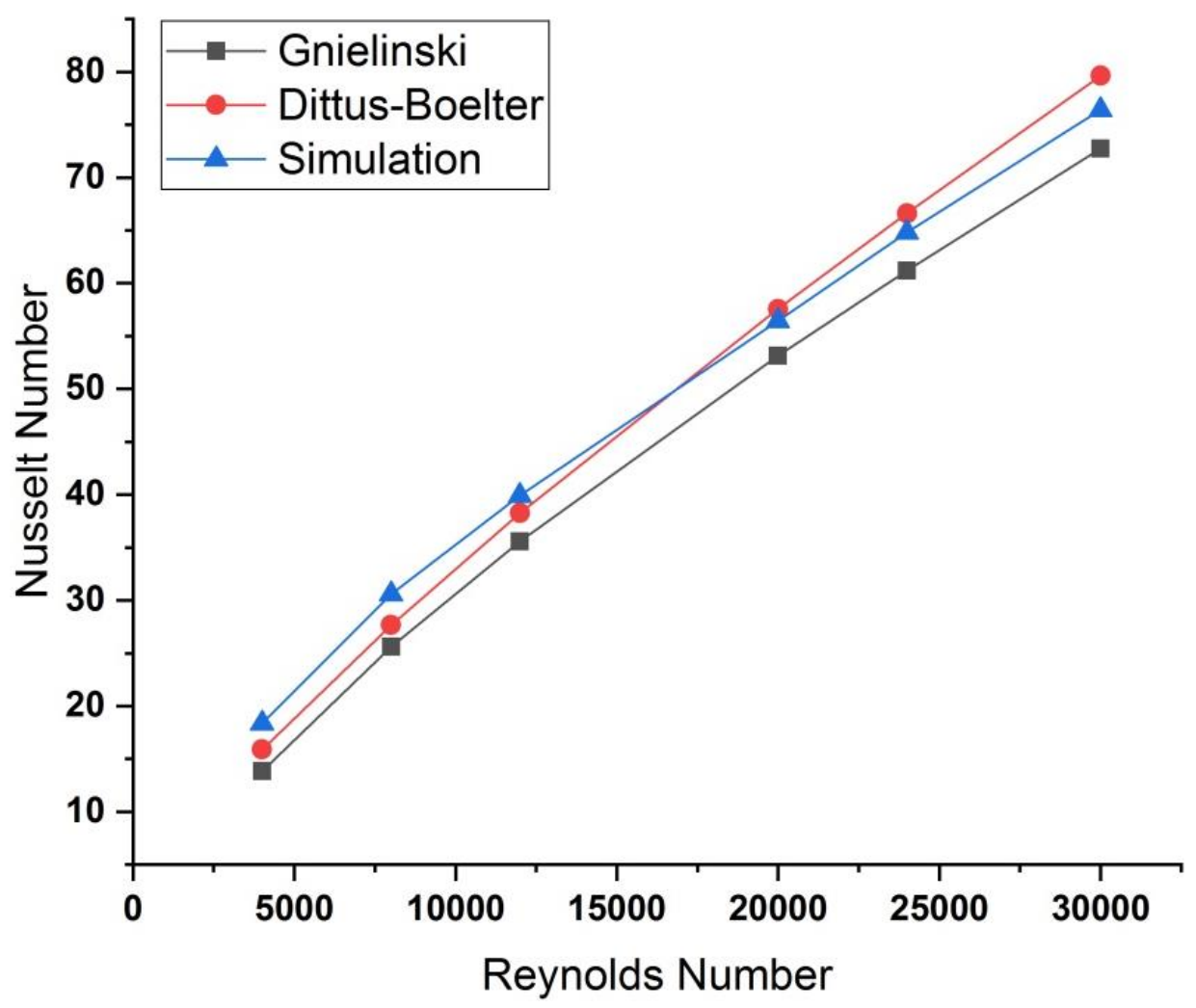

Figure 4. Nu Vs Re for smooth pipe

Figure 4 shows the comparison of the Nusselt number of present simulation with Gnielinski and DittusBoelter correlation having a percentage difference of 5.095 and 1.93 respectively. Friction factor with respect to the Reynolds number is determined by the Blasius and Petukhov correlation in a smooth tube.

The Blasius correlation for $4 \times 10^{3}<\operatorname{Re}<1 \times 10^{5}$

$$
f=0.316 / R e^{1 / 4}
$$

The Petukhov correlation for friction factor is

$$
f=(0.79 \ln R e-1.64)^{-2}
$$




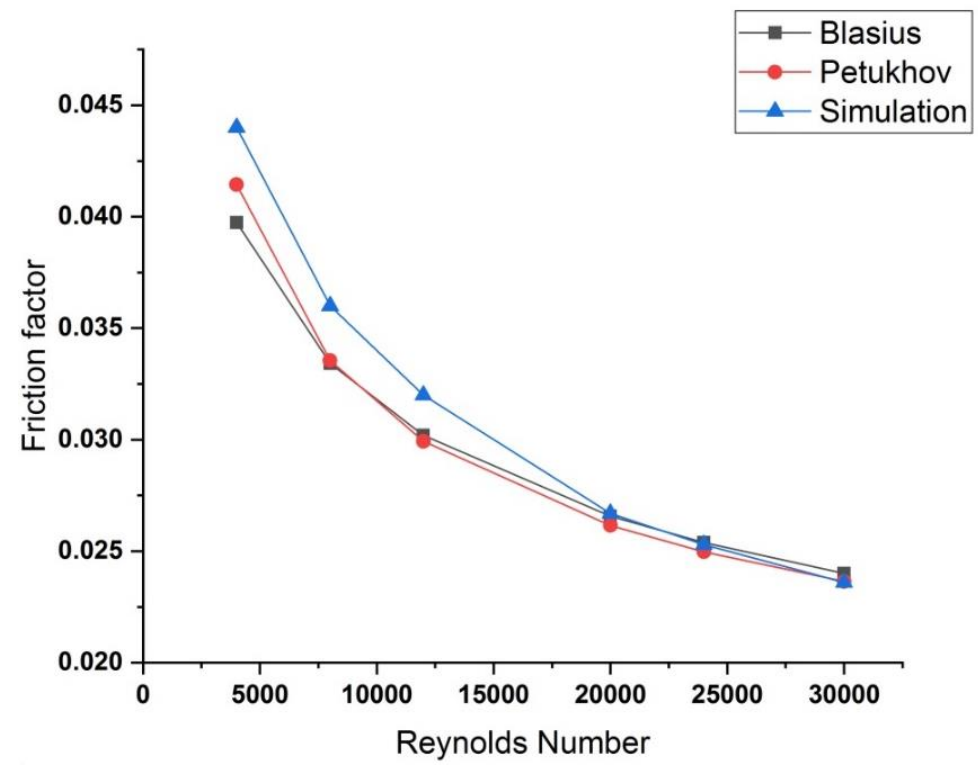

Figure 5. $f$ Vs Re for smooth pipe

Figure 5 shows the comparison of the friction factor of present simulation with Blasius and Petukhov correlation having a percentage difference of 4.74 and 0.34 respectively.

\section{Effect of LWT on Thermal Characteristics}

The effect of LWT on thermal characteristics has been studied through the value of the Nusselt number. The variation of Nusselt number with different slope angle and Reynolds number in comparison with a plain tube is displayed in figure 6. The increase in the Nusselt number results in an increase in temperature distribution inside the heat exchanger. Results in enhancing the heat transfer coefficient between hot and cold fluids. The Nusselt number increases with an increase of slope angle $5^{0}, 10^{\circ}, 15^{\circ}$ and $21^{\circ}$. The variation of Nusselt number at $21^{\circ}$ shows to be almost near to that of $15^{\circ}$, which will be discussed in the latter part.

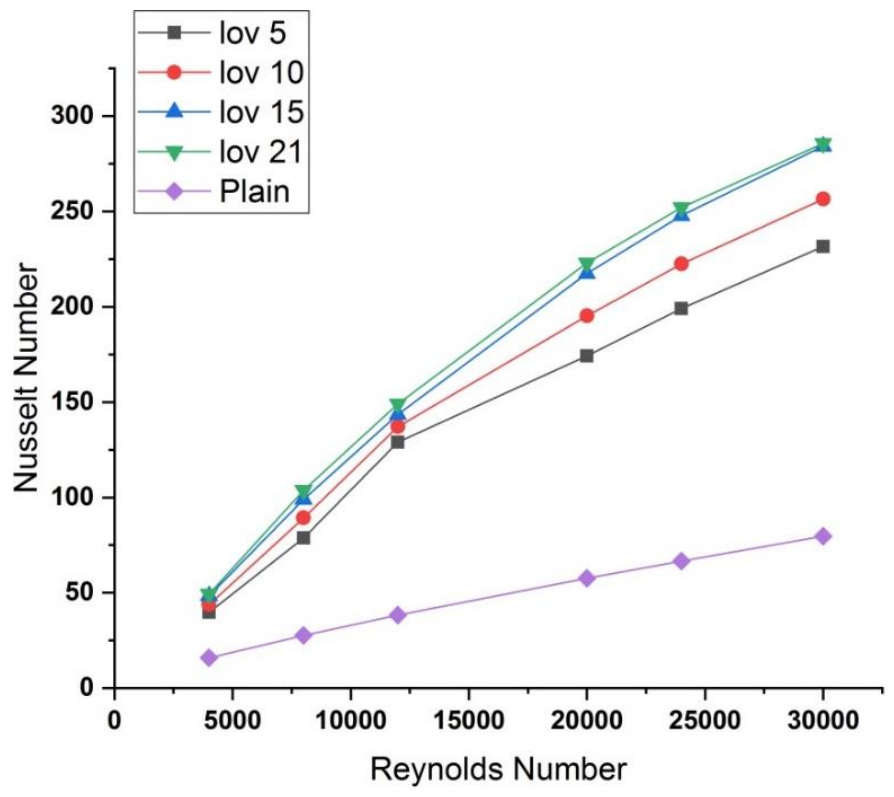

Figure 6. Nu Vs Re for LWT 
Figure 7 shows the distribution of the temperature between the smooth pipe and enhanced tube with LWT at Reynolds number 12000 with different $\mathrm{x} / \mathrm{d}_{\mathrm{i} 1}$ cross-sections. The temperature contours show that a better distribution of the temperature can be obtained by incorporating the LWT inside the tube. More evenly distribution of temperature can be seen in the tube with LWT when compared with the smooth tube. The phenomenon of temperature distribution at different cross-section can be further explained through streamlines contour. Figure 7 shows the streamline contours for different $\mathrm{x} / \mathrm{d}_{\mathrm{i} 1}$ cross-section in comparison with smooth pipe and enhanced tube. The streamlines contour shows that the greater the slope angle is higher the growth of vortices. A smaller slope angle low-intensity vortex can be found near the corners and high-intensity vortex can be seen at the center region of the pipe. The vortex generated on top region is seen to reach for greater areas when compared to the vortex at bottom. The vortex on both the sides gets intensified to larger region when the slope angle increases, including near the corners. Finally the development of the vortexes inside tube intensifies the heat transfer rate between the two flowing fluids. The percentage of increase of Nusselt number from the results were found to be $237.04 \%, 258.4 \%, 275.11 \%$, and $289.72 \%$ when compared to smooth pipe with respect to slope angle of $5^{0}, 10^{0}, 15^{0}$ and $21^{0}$, respectively.

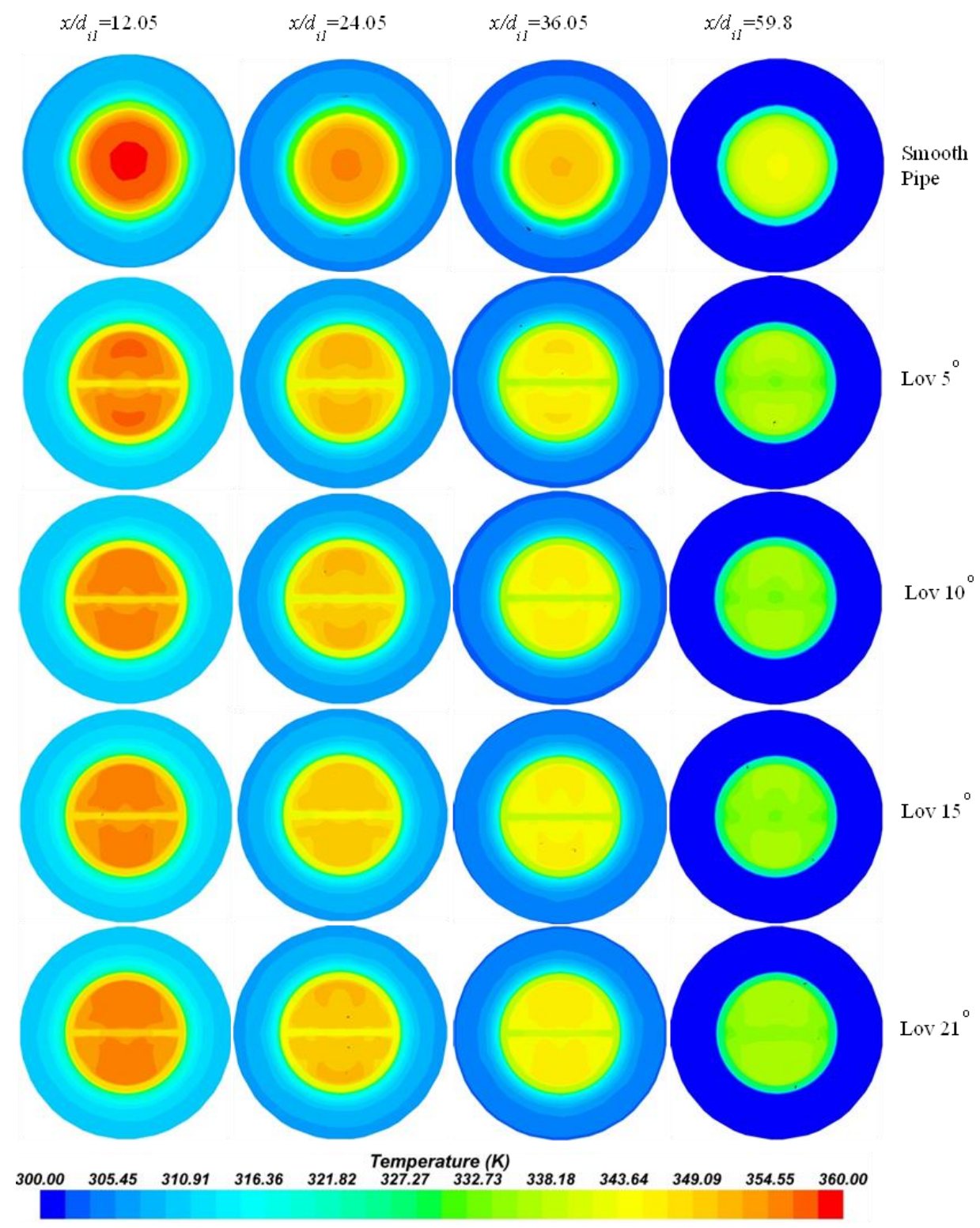

Figure 7. Temperature distribution at $\mathrm{Re}=12000$ 
Journal of Thermal Engineering, Research Article Vol. 6, No. 5, pp. 843-857, October, 2020

$x / d_{i I}=12.05$

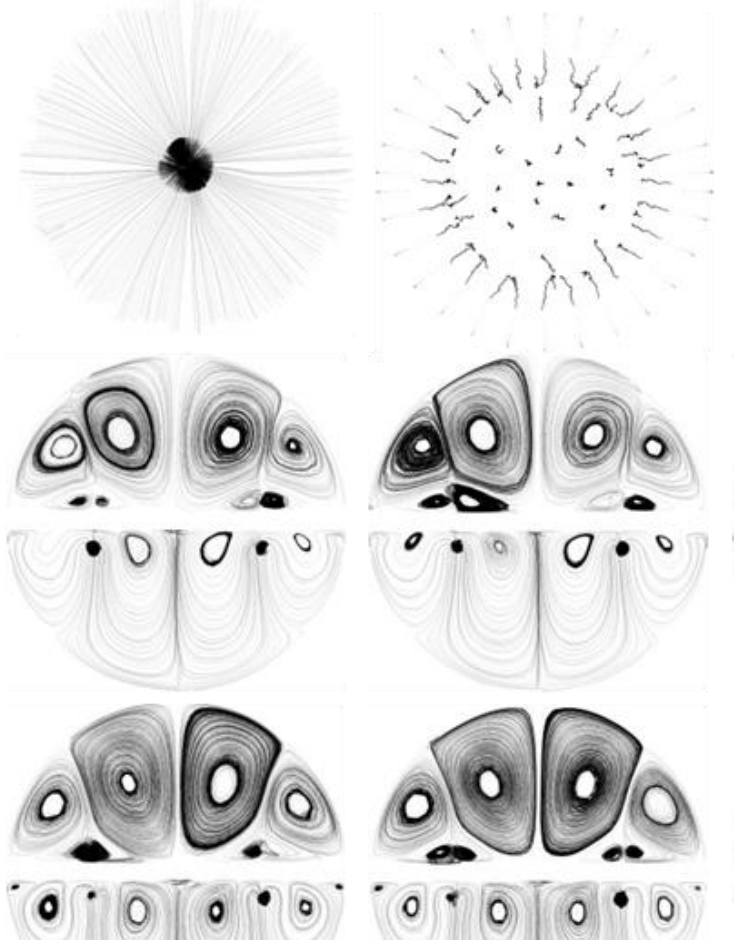

$x / d_{i I}=36.05$

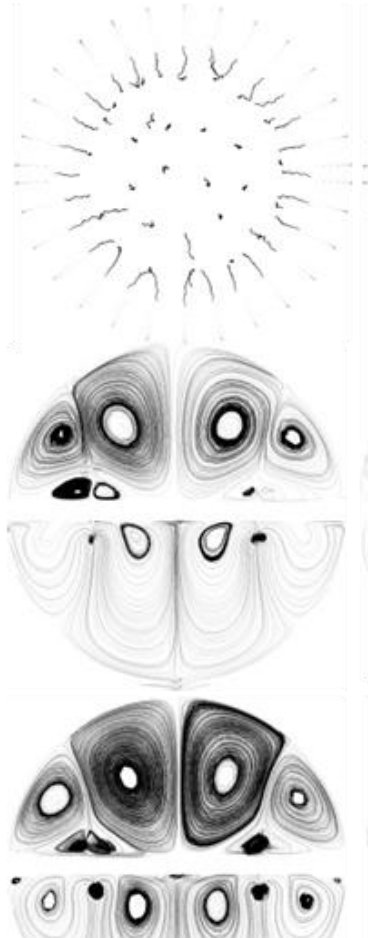

$x / d_{i I}=59.8$

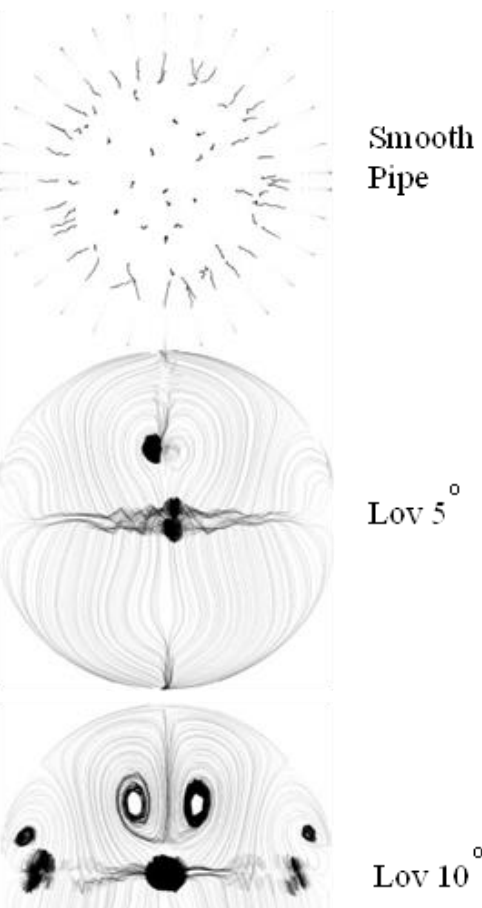

$\circ 0$
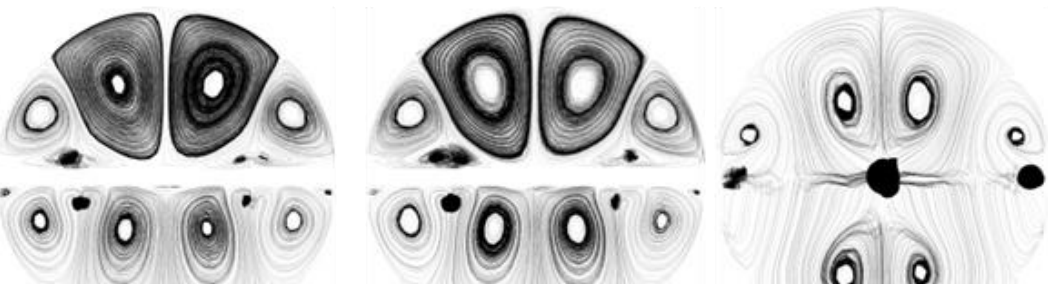

$\operatorname{Lov} 15^{\circ}$
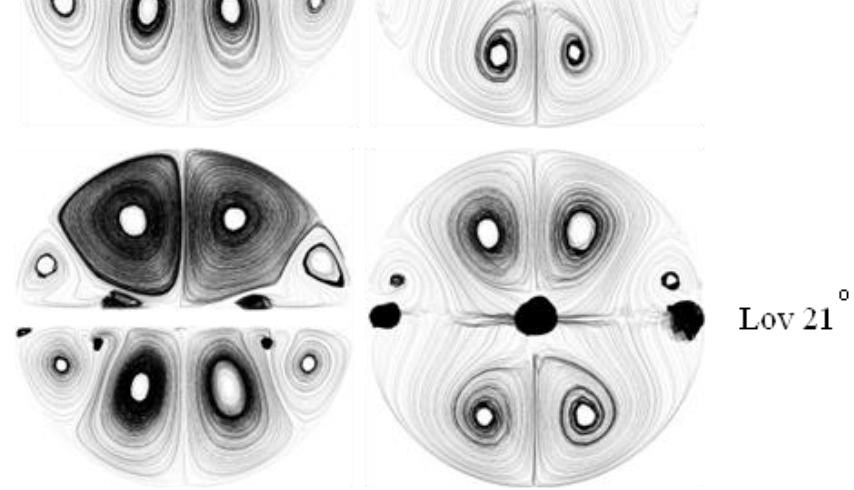

Figure 8. Streamlines at $\mathrm{Re}=12000$

\section{Effect of LWT on Fluid friction characteristics}

Figure 9 shows the variation of the friction factor with respect different slope angles of the LWT. It is proven concept that the friction factor reduces with respect to increase in the Reynolds number. The friction factor increase with the presence of LWT and this is due to increase of blockage area in the pipe. With the increase in the slope angle the friction factor also increases at respective Reynolds number. Figure 10 shows the velocity contours of LWT in comparison with smooth pipe at Reynolds number 12000. 


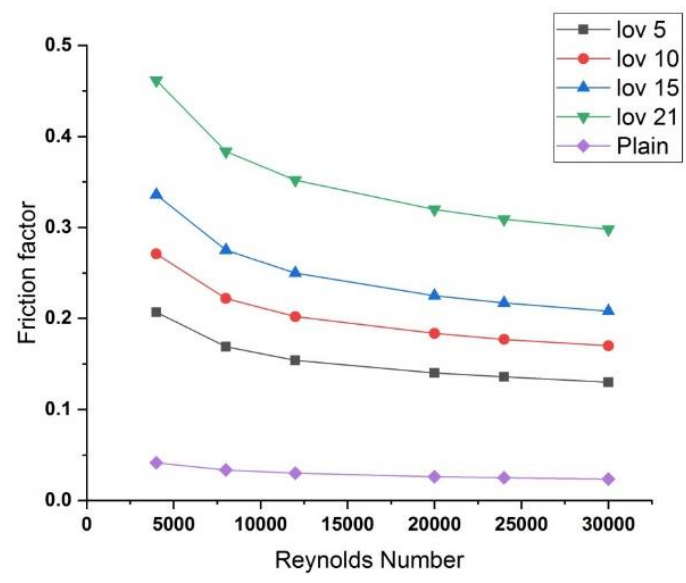

Figure 9. $f$ Vs Re for LWT

The blockage area can be easily rectified by figure 10 . The velocity contour is very smooth for the smooth pipe, where else the velocity contour for pipe with LWT shows lot of turbulence and recirculation. The friction near the wall will increase the friction factor as an increase in pressure drop when compared to smooth pipe. From the figure 10 velocity field intensify with the increase of slope angle up to $15^{\circ}$ and reduces at $21^{\circ}$. From the figure 9 it is observed that the amount of increase in the friction factor in comparison with plain tube is 5.13, 6.73, 8.33, and 11.73 times of that of smooth pipe with respect to slope angle of $5^{0}, 10^{0}, 15^{0}$ and $21^{0}$, respectively. So the numerical results from figures 7, 8 and 10 give a clear idea of the physical phenomenon of flow regime.

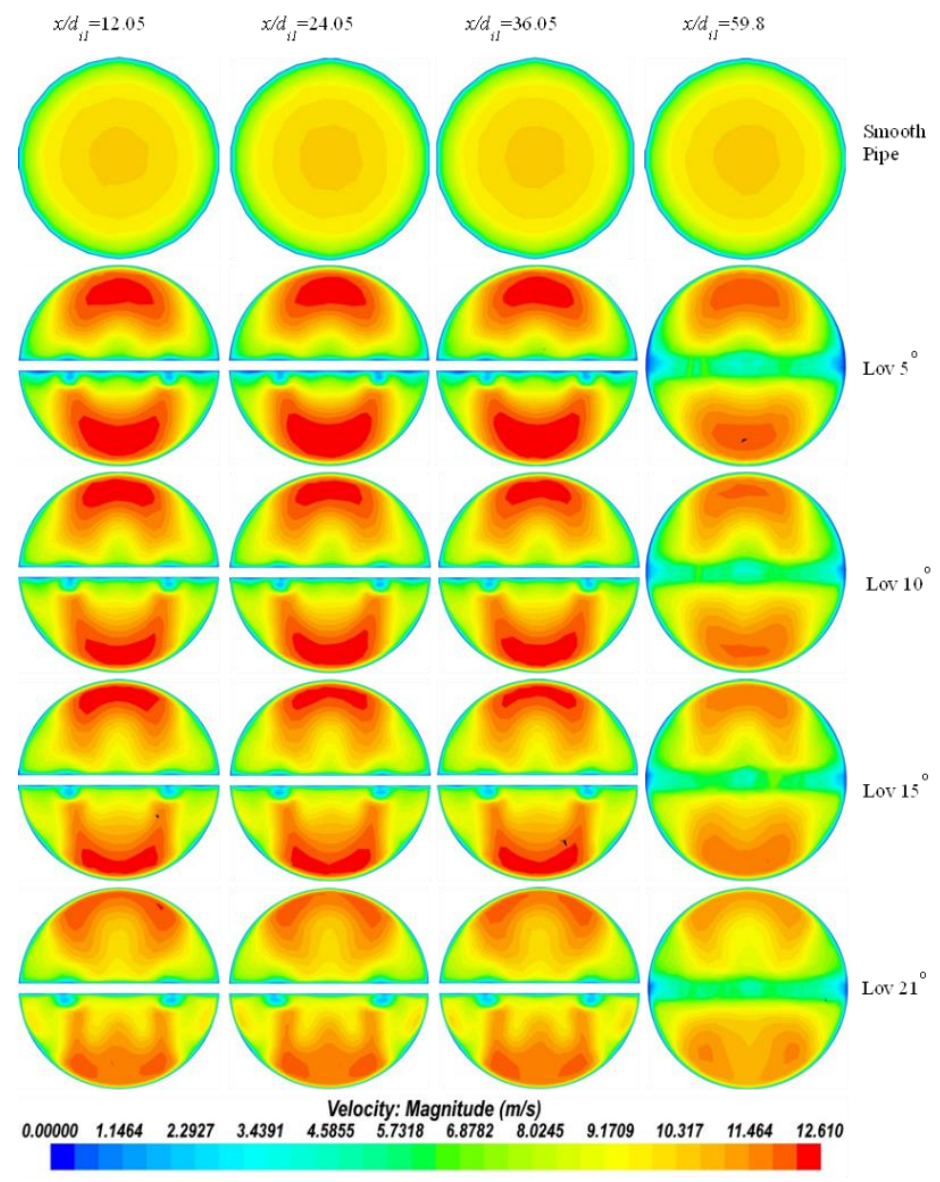

Figure 10. Velocity contour at $\mathrm{Re}=12000$ 


\section{Thermo-Hydraulic Performance Index}

The LWT inserts enhance the rate of heat transfer with an increase in flow friction. The method proposed by Webb [21] is generally adopted by researchers to evaluate the performance of a particular insert. Equation 11 shows the proposed method in its numerical form;

$$
T H P I=\frac{N u_{L} / N u_{s}}{\left(f_{L} / f_{S}\right)^{1 / 3}}
$$

Where it denotes the ratio of Nusselt number to that of Friction factor with respect to the augmented and smooth tube.

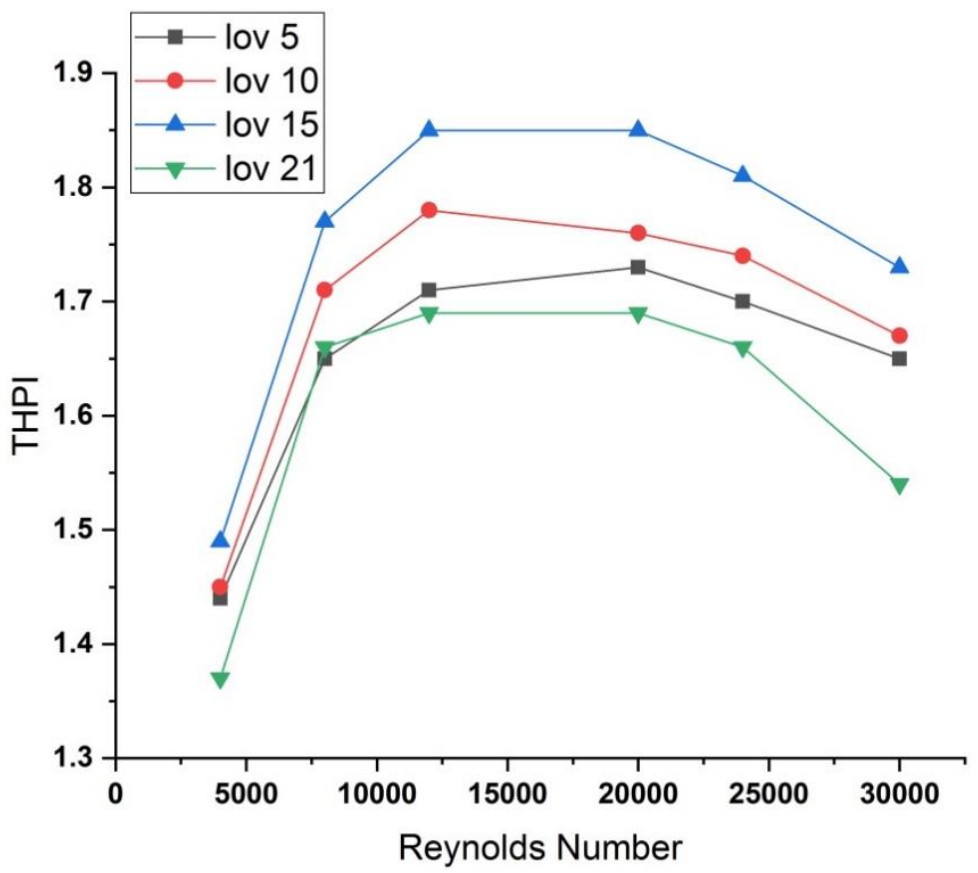

Figure 11. Thermo-hydraulic performance index

Figure 11 shows the thermo-hydraulic performance index (THPI) with respect to the Reynolds number. The analysis was carried out from Reynolds number 4000 as low-30000 as high. From figure 11, the performance of the LWT at Reynolds number 4000 was found to be lower for all the LWT slope angles. Similarly, the performance of LWT at Reynolds number 12000 was found to be high for all the LWT slope angles. However the angle of attack $15^{0}$ was found to be very superior when compared to other slope angles. The angle of attack $21^{0}$ was found to be very inferior when compared to other slope angles. The maximum THPI of 1.71, 1.78, 1.85 and 1.69 was observed at Reynolds number 12000 for slope angle of $5^{\circ}, 10^{\circ}, 15^{0}$ and $21^{0}$.

\section{Comparison with past research works}

The thermo-hydraulic performance index of louvered winglet tape has been compared with recent studies on heat transfer enhancement, namely curved winglet, delta winglet, louvered strip insert, and triple wing vortex generators. The slope angle of $15^{\circ}$ LWT is compared with punched delta-winglet vortex generator[12] of $\mathrm{P}=2 \mathrm{D}$, perforated curved winglet tape [8] of $\mathrm{d}=1.5 \mathrm{~mm}$, louvered strip insert[23] of slant angle $25^{\circ}$, perforated triple wing vortex generator[9] of $\beta=30 \% \mathrm{TR}=2$ and punched delta-winglet vortex generator[14] of $\mathrm{B}_{\mathrm{R}}=0.3 \mathrm{P}_{\mathrm{R}}=2$. Figure 12 displays the comparison of LWT with other vortex generators. The maximum THPI of 1.85 is attained at Re 12000 by LWT with an increment of $16.35 \%, 24.43 \%, 28.85 \%, 32.79 \%$ and 40.6\%, respectively, PCWT [8], PTWVG[9], PDWVG[14], PDWVG[12] and Louvered strip [23]. 


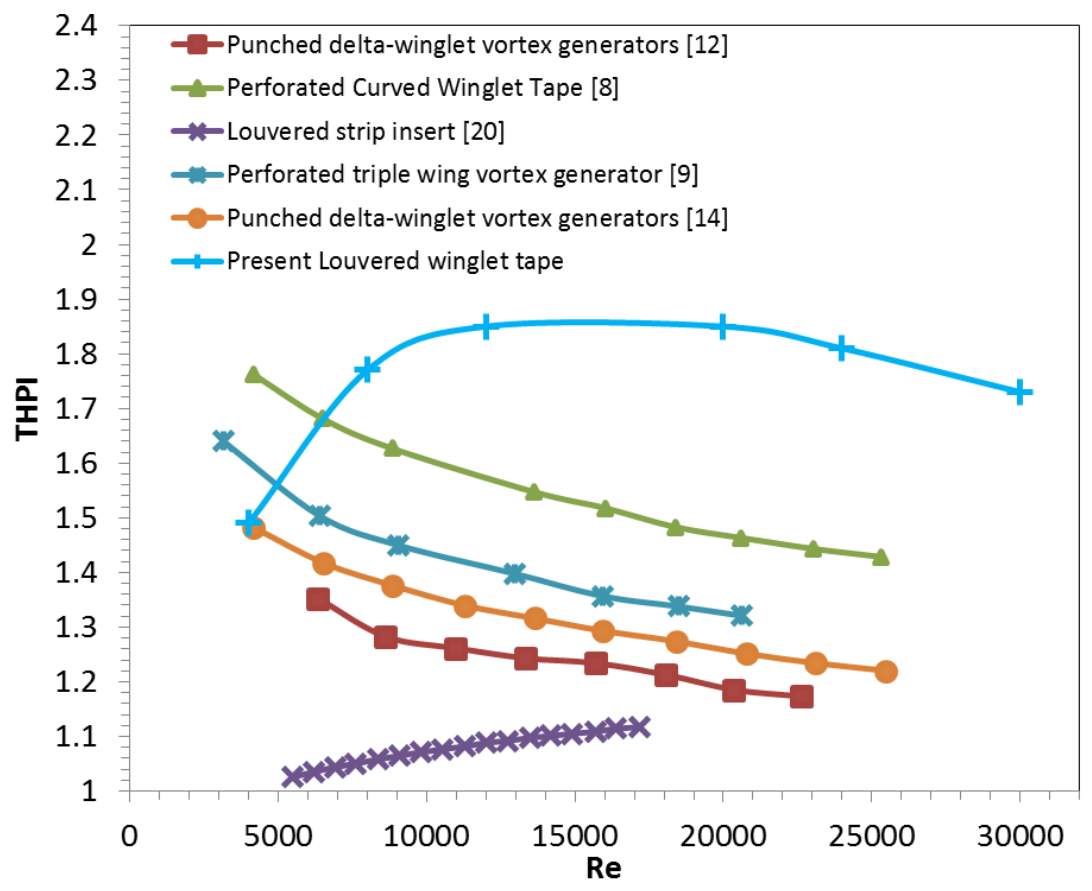

Figure 12. Comparison of thermo-hydraulic performance index with previous studies

\section{CONCLUSION}

The 3D numerical simulation was successfully carried out on LWT with a slope angle of $5^{\circ}, 10^{\circ}, 15^{\circ}$ and $21^{\circ}$. The effect of heat transfer and friction coefficient was examined on LWT for Reynolds number and slope angle varying form 4000-30000 and $5^{0}-21^{0}$, respectively. The findings from the current research are as follows:

1. Application of the LWT in the DPHE has resulted in increases of $\mathrm{Nu}$ and $f$. The friction factor is observed to be in the path of decrement when Reynolds number increases and this trend is followed by different slope angle of LWT.

2. The maximum value of THPI, friction factor and Nusselt number was found to be at Reynolds number 12000 for the slope angle $15^{\circ}$.

3. The LWT with slope angle $15^{\circ}$ has shown to be promising with respect to higher THPI when considering with other slope angle of $5^{0}, 10^{\circ}$, and $21^{\circ}$. The maximum THPI of 1.85 was obtained for slope angle $15^{\circ}$ at $\mathrm{Re}$ 12000. Similarly, the THPI values for other slope angle $5^{\circ}, 10^{\circ}$, and $21^{\circ}$ are $1.71,1.78$ and 1.69.

4. The 3D simulations on LWT are shown to be very promising when compares to other DWT of recent trends and the comparison graph is also shown in figure 12.

\section{FUNDING}

No funding was received for the research to accomplish.

\section{ACKNOWLEDGMENTS}

We are very much thankful to CHRIST Deemed to be University, Bangalore, to extend their support to investigate the current research in Numerical Simulation Laboratory in Department of Mechanical and Automobile Engineering, Faculty of Engineering. The authors wish to thank the HOD, Dean, Campus Director, Director, and ViceChancellor of CHRIST Deemed to be University for their immense support and guidance in accomplishing the work.

\section{CONFLICTS OF INTEREST}

The author pronounces no dispute on the present work. 


\section{NOMENCLATURE}

$\begin{array}{ll}L & \begin{array}{l}\text { length of the test section }(\mathrm{mm}) \\ t\end{array} \\ d & \text { tube thickness }(\mathrm{mm}) \\ D & \text { diameter of the inner tube }(\mathrm{mm}) \\ P & \text { Pitch distance between two consecutive LWT on the opposite side }(\mathrm{mm}) \\ P_{S} & \text { Pitch distance between two consecutive LWT on the same side }(\mathrm{mm}) \\ T & \text { temperature }(\mathrm{K}) \\ C_{p} & \text { specific heat of working fluid }(\mathrm{Kj} / \mathrm{kgK}) \\ P r & \text { Prandtl number } \\ R e & \text { Reynolds number } \\ N u & \text { Nusselt number } \\ f & \text { friction factor } \\ T H P I & \text { thermo-hydraulic performance index } \\ N u_{L} & \text { LWT Nusselt number } \\ N u_{S} & \text { smooth tube Nusselt number } \\ f_{L} & \text { LWT friction factor } \\ f_{S} & \text { smooth tube friction factor }\end{array}$

Greek Symbol

$\begin{array}{ll}\lambda & \text { slope angle of } \operatorname{LWT}\left({ }^{0}\right)=5^{0}, 10^{0}, 15^{0} \text { and } 21^{0} \\ \rho & \text { density of working fluid }\left(\mathrm{kg} / \mathrm{m}^{3}\right) \\ \Gamma & \text { thermal conductivity of working fluid }(\mathrm{W} / \mathrm{mK}) \\ \alpha & \text { thermal diffusivity of working fluid }\left(\mathrm{m}^{2} / \mathrm{s}\right) \\ \mu & \text { viscosity of working fluid (Pa.s) } \\ v & \text { Kinematic viscosity of working fluid }\left(\mathrm{m}^{2} / \mathrm{s}\right)\end{array}$

$\begin{array}{ll}\text { Subscripts } & \\ i & \text { internal } \\ e & \text { external } \\ 1 & \text { inner diameter } \\ 2 & \text { outer diameter }\end{array}$

\section{REFERENCES}

[1] Eiamsa-ard S, Promvonge P. Influence of Double-sided Delta-wing Tape Insert with Alternate-axes on Flow and Heat Transfer Characteristics in a Heat Exchanger Tube. Chinese J Chem Eng 2011;19:410-23. https://doi.org/10.1016/S1004-9541(11)60001-3.

[2] Chokphoemphun S, Tongyote P, Promvonge P, Jedsadaratanachai W, Chompookham T. Heat Transfer Augmentation in a Round Tube with $60^{\circ}$ Winglet Pair Inserts. Adv Mater Res 2014;931-932:1188-92. https://doi.org/10.4028/www.scientific.net/AMR.931-932.1188.

[3] Khoshvaght-Aliabadi M, Sartipzadeh O, Alizadeh A. An experimental study on vortex-generator insert with different arrangements of delta-winglets. 2015;82:629-39. https://doi.org/10.1016/j.energy.2015.01.072.

[4] Boonloi A, Jedsadaratanachai W. Turbulent forced convection in a heat exchanger square channel with wavyribs vortex generator. Chinese J Chem Eng 2015;23:1256-65. https://doi.org/10.1016/j.cjche.2015.04.001.

[5] Skullong S, Promvonge P, Jayranaiwachira N, Thianpong C. Experimental and numerical heat transfer 
investigation in a tubular heat exchanger with delta-wing tape inserts. Chem Eng Process Process Intensif 2016;109:164-77. https://doi.org/10.1016/j.cep.2016.09.005.

[6] Boonloi A, Jedsadaratanachai W. Flow topology, heat transfer characteristic and thermal performance in a circular tube heat exchanger inserted with punched delta winglet vortex generators. J Mech Sci Technol 2016;30:457-71. https://doi.org/10.1007/s12206-015-1251-2.

[7] Skullong S, Promvonge P, Thianpong C, Pimsarn M. Heat transfer and turbulent flow friction in a round tube with staggered-winglet perforated-tapes. Int J Heat Mass Transf 2016;95:230-42. https://doi.org/10.1016/j.ijheatmasstransfer.2015.12.007.

[8] Skullong S, Promvonge P, Thianpong C, Jayranaiwachira N, Pimsarn M. Thermal performance of heat exchanger tube inserted with curved-winglet tapes. Appl Therm Eng 2018;129:1197-211. https://doi.org/10.1016/j.applthermaleng.2017.10.110.

[9] Gautam A, Pandey L, Singh S. Influence of perforated triple wing vortex generator on a turbulent flow through a circular tube. Heat Mass Transf 2018;54:2009-21. https://doi.org/10.1007/s00231-018-2296-4.

[10] $\mathrm{Xu} \mathrm{Y,} \mathrm{Islam} \mathrm{MD,} \mathrm{Kharoua} \mathrm{N.} \mathrm{Numerical} \mathrm{study} \mathrm{of} \mathrm{winglets} \mathrm{vortex} \mathrm{generator} \mathrm{effects} \mathrm{on} \mathrm{thermal} \mathrm{performance} \mathrm{in}$ a circular pipe. Int J Therm Sci 2017;112:304-17. https://doi.org/10.1016/j.ijthermalsci.2016.10.015.

[11] Liang G, Islam MD, Kharoua N, Simmons R. Numerical study of heat transfer and flow behavior in a circular tube fitted with varying arrays of winglet vortex generators. Int $\mathrm{J}$ Therm Sci 2018;134:54-65. https://doi.org/10.1016/j.ijthermalsci.2018.08.004.

[12] Lei Y, Zheng F, Song C, Lyu Y. Improving the thermal hydraulic performance of a circular tube by using punched delta-winglet vortex generators. Int $\mathbf{J}$ Heat Mass Transf 2017;111:299-311. https://doi.org/10.1016/j.ijheatmasstransfer.2017.03.101.

[13] Wijayanta AT, Istanto T, Kariya K, Miyara A. Heat transfer enhancement of internal flow by inserting punched delta winglet vortex generators with various attack angles. Exp Therm Fluid Sci 2017;87:141-8. https://doi.org/10.1016/j.expthermflusci.2017.05.002.

[14] Khanoknaiyakarn C, Promvonge P, Thianpong C, Skullong S. Performance improvement in a tubular heat exchanger by punched delta-winglet vortex generators. IOP Conf Ser Mater Sci Eng 2018;297:012068. https://doi.org/10.1088/1757-899X/297/1/012068.

[15] Yaningsih I, Wijayanta A, Miyazaki T, Koyama S. Impact of Blockage Ratio on Thermal Performance of DeltaWinglet Vortex Generators. Appl Sci 2018;8:181. https://doi.org/10.3390/app8020181.

[16] Wijayanta A, Aziz M, Kariya K, Miyara A. Numerical Study of Heat Transfer Enhancement of Internal Flow Using Double-Sided Delta-Winglet Tape Insert. Energies 2018;11:3170. https://doi.org/10.3390/en11113170.

[17] Nalavade SP, Prabhune CL, Sane NK. Effect of novel flow divider type turbulators on fluid flow and heat transfer. Therm Sci Eng Prog 2019;9:322-31. https://doi.org/10.1016/j.tsep.2018.12.004.

[18] Keklikçioğlu O. A CFD Based Thermo-Hydroulic Performance Analysis in a Tube Fitted with Stepped Conical Nozzle Turbulators. J Therm Eng 2016;2:913-20. https://doi.org/10.18186/jte.76922.

[19] Bayareh M. Numerical Simulation and Analysis of Heat Transfer for Different Geometries of Corrugated Tubes in a Double Pipe Heat Exchanger. J Therm Eng 2019;5:293-301. https://doi.org/10.18186/thermal.581775.

[20] Pavan Kumar K, Siddhardha R, Rama Bhadri Raju C, Sudheer Kumar K. Response surface based optimization of ribbed isosceles triangular twisted tape heat exchanger using entropy augmentation generation number with Al2O3 nano working fluid. J Therm Eng 2019;5:210-21. https://doi.org/10.18186/thermal.544396.

[21] Eiamsa-ard S, Pethkool S, Thianpong C, Promvonge P. Turbulent flow heat transfer and pressure loss in a double pipe heat exchanger with louvered strip inserts. Int Commun Heat Mass Transf 2008;35:120-9. https://doi.org/10.1016/j.icheatmasstransfer.2007.07.003.

[22] Fan AW, Deng JJ, Nakayama A, Liu W. Parametric study on turbulent heat transfer and flow characteristics in a circular tube fitted with louvered strip inserts. Int J Heat Mass Transf 2012;55:5205-13. https://doi.org/10.1016/j.ijheatmasstransfer.2012.05.023.

[23] Yaningsih I, Wijayanta AT, Miyazaki T, Koyama S. Thermal hydraulic characteristics of turbulent single-phase flow in an enhanced tube using louvered strip insert with various slant angles. Int J Therm Sci 2018;134:35562. https://doi.org/10.1016/j.ijthermalsci.2018.08.025.

[24] Webb RL. Performance evaluation criteria for use of enhanced heat transfer surfaces in heat exchanger design. Int J Heat Mass Transf 1981;24:715-26. https://doi.org/10.1016/0017-9310(81)90015-6. 